\title{
Nges Siy (I love you): A Community-Based Youth Suicide Intervention in Northern British Columbia
}

\begin{abstract}
This youth suicide prevention research project is an example of a partnership between Carrier Sekani Family Services (CSFS) and the University of Northern British Columbia (UNBC), funded by the Canadian Institutes of Health Research (CIHR), Institute of Aboriginal Peoples' Health, that directly responds to goals of ethical research conducted in First Nations' communities. Through the use of mixed methods, the project investigated the effectiveness of community-based interventions in preventing suicide and tracked youth self-esteem, depression, and other indicators over the course of the project. The knowledge gained from this research project will help guide CSFS and its member communities in offering programs and services that will assist in reducing incidence of suicide.
\end{abstract}

\section{Keywords}

Community-based intervention, youth suicide, cultural continuity, First Nations, mental wellness, mental health, suicide prevention

\section{Authors}

Henry George Harder is an Indigenous scholar at UNBC. He is a professor in the School of Health Services and a registered psychologist. He has been living on Lheidli T'enneh territory for the past 14 years and has been assisting CSFS in their research for the past 12 years.

Travis Holyk is the executive director of Research, Primary Care, and Strategic Services at CSFS, where he has been since 2002. Holyk along with Darcy Dennis, member of the Lake Babine Nation and research manager for the youth suicide research project, developed and participated in all of the culture camps and canoe journeys with Carrier and Sekani youth conducted as part of the study.

Virginia Russell is a scholar with Métis heritage and a doctoral student in the School of Health Sciences at UNBC. She was raised in northern BC and spent time living and working in the Tsay Keh Dene community. She has been on Lheidli T'enneh territory for the past 7 years.

Tammy Klassen-Ross was raised in Vanderhoof, BC, on Saik'uz territory and has lived on Lheidli T'enneh territory for 8 years. She is a graduate of UNBC and is now an instructor in the School of Health Sciences.

While we four have worked together on writing about this research, many others were also involved over the 6-year course of the work.

\section{Acknowledgements}

The authors would like to acknowledge and thank the leadership of Carrier Sekani Family Services who conceptualized and supported this research. In particular we would like to acknowledge the great work, support, and generous spirit of the Elders and youth members of the Leadership Advisory Council without whom this work would not have been possible. Finally, we 
Nges Siy (I love you): A Community-Based Youth Suicide Intervention in Northern British Columbia • Henry G. Harder, Travis Holyk, Virginia L. Russell, Tammy Klassen-Ross

would like to thank the Institute of Aboriginal Peoples Health - Canadian Institutes of Health Research for funding this work. Mussi Cho!

\section{Introduction}

"I used to be so ashamed of being native and now I'm not ... so yeah, it made me happy for who I am and where I come from." (Participant 2)

Aboriginal $^{1}$ Peoples', and specifically First Nations', health is deeply impacted by social determinants including those related to the impacts of colonization and its resultant intergenerational traumas (Hankivsky \& Christoffersen, 2008; Marmot, Friel, Bell, Howeling, \& Taylor, 2008). As a result, Aboriginal Peoples in Canada experience a unique set of mental health challenges (Loppie Reading \& Wien, 2009). Mental illness and social issues such as substance abuse, addiction, and suicide are particularly high among Aboriginal Peoples (Royal Commission on Aboriginal Peoples, 1996). Post-traumatic stress disorder, substance misuse disorder, and depression and other mood disorders are common types of mental illness among Aboriginal Peoples, often associated with colonial trauma and the effects of residential school and/or the foster care system; these illnesses are also frequently misunderstood by the general population (Adelson, 2005; Aguiar \& Halseth, 2015; Blackstock, 2011; Chansonneuve, 2005).

Suicide rates among First Nations people in Canada are extraordinarily high in comparison to the general population (Chandler \& Lalonde, 1998). These disparities are particularly evident for young First Nations men. For example, First Nations male youth (ages 15-24) have a suicide rate of 126 per 100,000, which is roughly 5 times the rate of non-First Nations youth. Similarly, young First Nations women have a suicide rate 7 times higher than non-First Nations women. Suicide and self-inflicted injuries are a leading cause of death for Canadian First Nations youth and young adults (Health Canada, 2010).

The Mental Health Commission of Canada (2012) outlines the importance of cultural competence and safety as well as the integration of traditional knowledge, customs, and practices when addressing mental health problems for Aboriginal Peoples. The commission further stresses the substantial role that the intergenerational and vicarious nature of trauma plays when addressing community wellness (Mental Health Commission of Canada, 2012).

The Carrier Sekani First Nations of northern British Columbia (BC), Canada, have their own institutions for maintaining language, governance, health, and knowledge related to all aspects of life. Carrier legal systems, such as the bah'lats, are situated to address governance of knowledge generated from within their communities and provide mechanisms for the protection of individual and community knowledge. The suicide prevention research project described in this paper promoted Carrier systems as the core intervention strategies, including the development of a community-led suicide intervention resource manual based on Carrier values and the creation and provision of what became known as "culture camps."

\section{Background}

This project represents the ongoing partnership between Carrier Sekani Family Services (CSFS), an organization responsible for health, social, legal, and research services for 11

\footnotetext{
${ }^{1}$ The term Aboriginal refers to persons who self-identify as First Nations (North American Indian), Métis, or Inuit and/or are treaty or registered Indians as defined by the Indian Act of Canada (1867) and/or are members of an Indian band or First Nation (Statistics Canada, 2011).
} 
Nges Siy (I love you): A Community-Based Youth Suicide Intervention in Northern British Columbia • Henry G. Harder, Travis Holyk, Virginia L. Russell, Tammy Klassen-Ross

member First Nations organizations, and the University of Northern BC (UNBC). As much as the research, funded by Canadian Institutes of Health Research (CIHR), was about addressing suicide, it was also about building capacity of nations to define the issue of suicide through their lens and to develop community-specific interventions. Carrier and Sekani people maintain that they have an inherent Aboriginal right to be self-determining, which includes the ability to use Carrier and Sekani institutions in maintaining social order in their communities (Holyk, Shawana, \& Adam, 2005). Assuming responsibility for the care and protection of children, as well as the maintenance of family structures and governance systems, is an expression of selfdetermination that was supported by the research team both in the manner the research was carried out and the structure of the team.

The connection to community was developed through such measures as the establishment of a Leadership Advisory Council (LAC), consisting of Elder and youth representatives from each of the 11 communities who guided the research and intervention each step of the way, resulting in the continuity of interventions as well as relationships with community members. Bringing Western and Indigenous ways of knowing together has been and continues to be a struggle, and we are actively engaged in that struggle. As a research team focused on Indigenous issues, comprising Indigenous and non-Indigenous persons, we are committed to placing Indigenous epistemology and ontology at the core of our work.

The province of BC is home to 203 First Nations groups, the highest number of nations in comparison to all other provinces and territories in Canada. Aboriginal people in BC represent approximately $5.4 \%$ of the total population, with the highest number residing in the northern part of the province (Statistics Canada, 2015). Even within the many First Nations in BC, there are further language and cultural groupings with diversity even among sub-groups. This is reflected within the Carrier and Sekani nations, where there are distinct groupings that maintain geographic, cultural, and linguistic variation. According to Carrier linguists and community members, there are six distinct Carrier linguistic dialects: Babine, Cheslatta, Nakazd'li, Saik'uz, Lheidli T'enneh, and Wet'suwet'en. Much like diversity in language, there are important nuances in the Carrier clan structure and bah'lats system.

In 1990, in response to the social and health challenges facing First Nations and as a way to re-establish control over health and social systems, 11 Carrier and Sekani nations formed the organization presently named Carrier Sekani Family Services. CSFS has worked hard to reassert control in areas that have been sources of attack on community values and teachings, such as maintenance of Carrier governance systems, community wellness, and preservation of family and guardianship of children.

The key governance structure among the Carrier Sekani people is the potlatch or bah'lats system. Bah'lats are organized around a clan system and are the core cultural, economic, political, social, legal, and spiritual institution of the Carrier Sekani people. While protocols are flexible and adaptive to the differing systems of each community, the guiding principles of the bah'lats system are shared among the communities (Holyk, Shawana, \& Adam, 2005). The bah'lats is inclusive of all members of the nation with all members belonging to a clan. There are four primary clans, Bear, Caribou, Frog, and Beaver, each with several sub-clans. Generally, there is one head clansman for each primary clan, and a hereditary chief who holds rank in the bah'lats as a wing chief represents each sub-clan. These positions are passed down through family or clan lineages as well as resulting from selections guided by clan Elders. As with many First Nations communities, leaders express concerns about the disconnect between elders and youth and the impacts it has on Carrier Sekani society. 
Nges Siy (I love you): A Community-Based Youth Suicide Intervention in Northern British Columbia • Henry G. Harder, Travis Holyk, Virginia L. Russell, Tammy Klassen-Ross

BC Aboriginal populations are, on average, younger than all other ethnicities, with a median age of 29 compared to 42 in the general society (BC Statistics, 2013). Similar to provincial population statistics, one quarter of the population on reserve represented by CSFS are youth aged 13-25 years.

Table 1

Total and Youth Population on Reserve by CSFS Community

\begin{tabular}{|l|c|c|}
\hline \multicolumn{1}{|c|}{ Community Name } & Total Population & Youth (Ages 13-25) \\
\hline Saik'uz (Stoney Creek) & 437 & 116 \\
\hline Wet'suwet'en & 97 & 24 \\
\hline Burns Lake Band & 48 & 0 \\
\hline Cheslatta & 166 & 36 \\
\hline Nadleh Whut'en (Nautley) & 240 & 59 \\
\hline Stellat'en (Stellaquo) & 219 & 50 \\
\hline Takla Lake & 401 & 114 \\
\hline Skin Tyee & 59 & 10 \\
\hline Yekochee & 102 & 24 \\
\hline Nee Tahi Buhn & 56 & 22 \\
\hline Lake Babine Nation & 1447 & 379 \\
\hline
\end{tabular}

Source: Aboriginal Affairs and Northern Development Canada, 2012

\section{Research Methodologies and Methods}

This project employed a mixed-methods approach. Quantitative data gathered from questionnaires (pre- and post-intervention) were entered into and analyzed using a statistical analysis program In addition to quantitative questionnaires, the research team completed qualitative interviews with the majority of youth participants as well as elders and leadership. Once the project was complete in 2013, the qualitative data were coded and analyzed. For the interviews the analysis followed a thematic analysis approach (Braun \& Clarke, 2006). The thematic analysis of the interview data was informed by interpretive phenomenology (Lopez \& Willis, 2004) and decolonizing and critical Indigenous methodologies (Battiste, Bell, \& Findlay, 2002; Denzin, Lincoln, \& Smith, 2008; Smith, 2012). The overall project was completed using community-based participatory approaches (Brown, 1991; Israel, Schulz, Parker, \& Becker, 1998).

In keeping with the principles of participatory research, the project began in December 2006 with a community consultation meeting with the goal of seeking input around issues related to youth suicide in community and to begin a process of selecting individuals who would be able to assist in developing the research project. The research team provided invitations to Chief and Council to recommend participants from groupings of youth, Elders, and traditional knowledge holders to attend the consultation meeting. A total of 68 community members participated in the meeting, one half of whom were youth. Key messages that formed the foundation of the project included:

- Culture is a key to addressing healing.

- Drug and alcohol abuse must be addressed.

- Physical, sexual, mental, and emotional abuse are significant factors. 
Nges Siy (I love you): A Community-Based Youth Suicide Intervention in Northern British Columbia • Henry G. Harder, Travis Holyk, Virginia L. Russell, Tammy Klassen-Ross

- There is a disconnect between elders and youth due to child apprehensions and residential school.

- There is a lack of healthy activities for youth in community.

Stemming from the meeting, a LAC with one Elder and one youth representative chosen by and from each participating community was formed to provide project guidance. Community leaders as well as the LAC were involved in all aspects of the project from design to dissemination. The research team also included members of nations who participated in the camps and youth suicide manual training and who assisted with administering the questionnaires, data entry, and dissemination. Participants took part in events such as culture camps and helped develop and implement a youth suicide prevention manual, measures that were determined by the LAC to be means of addressing the key messages. These materials are available to all member nations.

Beginning in 2007, youth between the ages of 13 and 25 were recruited to this study from communities served by CSFS based on the recommendation of community leaders, the LAC, and individuals on the research team. Standardized measures inquiring about depression status, suicide ideation, and self-esteem were administered to youth prior to and upon the completion of the cultural event. For the standardized tests, youth were tested the first day of camp and either the day they left camp or the night before they left. Interviews and focus groups with youth and communities were also used to better understand if and how engagement in these activities improved participants' understanding of their traditional culture, overall well-being, and ability to form a more comprehensive picture of their collective experiences. The findings from the qualitative data were reviewed and their interpretation agreed upon by the LAC.

The LAC played an instrumental role in the development of the suicide awareness and prevention manual entitled Nges Siy (I love you). After a great deal of discussion, examination of other traditions, and consultation the LAC decided that the training and resulting manual should be organized around eight strong Carrier Sekani values: Respect, Compassion, Wisdom, Responsibility, Caring, Sharing, Harmony, and Balance. These values were interwoven into intervention materials. Members of the LAC participated in interviews as part of the manual's development and also met to provide feedback on each draft of the manual.

\section{Measures}

All participants in this research study gave written consent to be involved in the study, including the assessment process. Consent was obtained before every separate assessment occasion. In the case of minors, consent was obtained from the parent or guardian. After a thorough and extensive search for Indigenous measures, it was decided to use the following, most widely accepted assessment measures. These measures are not Indigenous, and this is a major limitation of this study. There is a clearly demonstrated need for more appropriate instruments and/or assessment procedures to be developed and accepted.

- The Beck Depression Inventory-II (BDI-II) is a 21-item self-report inventory that assesses the presence of symptoms associated with depression. Participants were asked to indicate the degree of each symptom as it applies to them on a 4-point Likert-type scale from not present (0) to severe (3) (Beck, Steer, \& Brown, 1996).

- The Beck Scale for Suicide Ideation is a 21-item self-report instrument for assessing and monitoring suicide risk. The scale is divided into three sections: 1) attitudes toward living and dying, 2) suicidal ideation and anticipated reactions to those thoughts, and 3) previous suicide attempts and seriousness of intent (Beck \& Steer, 1991). 
Nges Siy (I love you): A Community-Based Youth Suicide Intervention in Northern British Columbia • Henry G. Harder, Travis Holyk, Virginia L. Russell, Tammy Klassen-Ross

- Developed from the BDI-II, the Beck Hopelessness Scale (BHS) is a 20-item self-report instrument used to assess hopelessness, particularly in relation to suicide risk. The three major aspects measured with this instrument include feelings about the future, loss of motivation, and expectations (Beck \& Steer, 1988).

- The Rosenberg Self-Esteem Scale is one of the most commonly used self-esteem measures in social science research. The 10-item scale measures global self-worth, examining positive and negative feelings about the self. Items are answered on a 4-point Likert scale ranging from strongly disagree (4) to strongly agree (1) (Rosenberg, 1965).

\section{Results and Discussion}

\section{Participants}

A total of 130 youth (62 males and 68 females) from Carrier Sekani communities, with an average age of 14.85 years $(S D=1.88)$, participated in nine separate cultural camps (see Table 2); many youth participated in more than one camp. Activities within these camps focused on traditional food gathering techniques, language, survival techniques, clan affiliation, and the bah'lats system.

Table 2

Number of Youth per Cultural Activity

\begin{tabular}{|l|c|c|c|}
\hline \multicolumn{1}{|c|}{ Camp Date } & Males & Females & Total \\
\hline Summer 2007 & 7 & 5 & 12 \\
\hline Winter 2008 & 6 & 4 & 10 \\
\hline Summer 2008 & 7 & 7 & 14 \\
\hline Winter 2009 & 8 & 13 & 21 \\
\hline Summer 2009 & 7 & 13 & 20 \\
\hline Winter 2010 & 2 & 8 & 10 \\
\hline Summer 2011 & 7 & 0 & 7 \\
\hline Summer 2012 & 11 & 9 & 20 \\
\hline
\end{tabular}

\section{Quantitative Results}

To determine if youth participation in culturally appropriate activities would reduce levels of depression, hopelessness, and suicide ideation and increase levels of self-esteem, four separate one-tailed paired sample $t$ tests were conducted on the Beck Depression Inventory, Beck Hopelessness Scale, Beck Suicide Scale, and the Rosenberg Self-Esteem Scale (see Table 3 for means and standard deviations). Results indicated that levels of depression, $t(109)=4.00, M=$ $2.55(S D=6.69), p<.01$; levels of hopelessness, $t(118)=2.71, M=0.91(S D=3.65), p<.01$; and levels of suicide ideation, $t(116)=3.06, M=1.15,(S D=4.08), p<.01$ significantly decreased after youth participated in culturally appropriate activities. Furthermore, results indicated that levels of self-esteem significantly increased after the youth participated in culturally appropriate activities $t(116)=-3.02, M=-1.36(S D=4.87), p<.01$. These results indicate that prior to engaging in culturally appropriate camps, youth self-reported higher levels of depression, hopelessness, and suicide ideation than when they left camp; furthermore, youth self-reported higher levels of self-esteem after they engaged in the culturally appropriate camps than when they arrived at camp. 
Nges Siy (I love you): A Community-Based Youth Suicide Intervention in Northern British Columbia • Henry G. Harder, Travis Holyk, Virginia L. Russell, Tammy Klassen-Ross

Table 3

Means and Standard Deviations for Standardized Measures

\begin{tabular}{|l|c|c|c|c|}
\hline \multirow{2}{*}{ Measure } & \multicolumn{2}{|c|}{ Pre-Camp } & \multicolumn{2}{c|}{ Post-Camp } \\
\cline { 2 - 5 } & Mean & SD & Mean & SD \\
\hline $\begin{array}{l}\text { Beck Depression } \\
\text { Inventory }\end{array}$ & 10.04 & 12.46 & 7.48 & 3.98 \\
\hline $\begin{array}{l}\text { Beck } \\
\begin{array}{l}\text { Hopelessness } \\
\text { Scale }\end{array}\end{array}$ & 4.09 & 3.95 & 3.18 & \\
\hline $\begin{array}{l}\text { Beck Suicide } \\
\text { Scale }\end{array}$ & 2.38 & 4.71 & 1.23 & 3.62 \\
\hline $\begin{array}{l}\text { Rosenberg Self- } \\
\text { Esteem Scale }\end{array}$ & 20.56 & 5.76 & 21.91 & 5.63 \\
\hline
\end{tabular}

To further determine if cultural activities increased youths' level of identification and knowledge of their traditional culture, a survey was administered upon the conclusion of the activities. Of the 130 total youth who participated in the activities, 58 youth completed the survey. Frequency analysis indicated that $87 \%$ of the youth felt their knowledge of the Carrier language had improved, $96 \%$ indicated their knowledge of their traditional culture had improved, $92 \%$ indicated their connection to the community Elders had improved, and $90 \%$ indicated that their opinion of themselves had improved. In regards to risk-taking behaviours, frequency analysis indicated $55 \%$ of youth had a reduced desire to drink alcohol and $58 \%$ of youth had a reduced desire to take illegal drugs.

\section{Qualitative Data}

Analysis of the interview and focus group data eventually coalesced around three themes.

\section{Cultural awareness, connection, and identity.}

"After the camp I felt very good, like I learned more about what culture is and who I actually am." (Participant 3)

In the context of suicide prevention, increased cultural awareness and connectivity can serve as extraordinarily important protective factors (Chandler \& Lalonde, 1998). In our results, both qualitative and quantitative data sets demonstrated that participants experienced increased awareness about and connectivity with their culture, customs, and practices as a direct result of attending and engaging in the culture camps. Participants made reference to various activities and practices that were culturally specific and culturally significant. Many participants spoke of how hearing and learning more about their culture and background added to their sense of belonging and identity. Some participants even went as far as to state that their sense of pride in themselves and their heritage and culture increased as a result of engaging in the project. For example, when speaking about the camp experience a participant said: "I was happy that I got to learn who I was as an Aboriginal youth. I used to be so ashamed of being native and now I'm not ... so yeah, it made me happy for who I am and where I come from" (Participant 2). Youth gained stronger connections with elders and culture and reported that this new-found awareness had a positive impact on their sense of identity. When asked about elder connections, Participant 
Nges Siy (I love you): A Community-Based Youth Suicide Intervention in Northern British Columbia • Henry G. Harder, Travis Holyk, Virginia L. Russell, Tammy Klassen-Ross

10 said, "[Grandmothers] are something really close to our culture and to have that, to feel it, that unconditional love, is the most powerful thing in the world."

Having a sense of belonging to or being part of their culture appeared to be important in that it helped participants feel they were part of something bigger than themselves; that they now "belonged" to a larger group, had a more defined place in society, a particular ancestry, history, heritage, which in turn helped the participants see themselves as more than just an individual. Participants made reference to their exposure to and learning about their culture, including: learning and speaking their language; engaging in "traditional" maintenance activities and practices such as catching, gutting, and smoking fish; cultural celebrations such as singing, drumming, and dancing; and gatherings such as potlatches. Youth felt activities were useful in increasing knowledge of traditional culture. There was a reported improvement in traditional language and enhanced relationships between elders and youth as a direct result of being involved in the project.

\section{Self-awareness, enhancement, and discovery.}

This theme is concerned with how, according to the participants, engaging and participating in culture camp added new layers of meaning to their lives. Participants made reference to experiences of self-awareness, enhancement, and discovery. They spoke of how culture camp helped them redefine themselves, their identity, and their place in the world. Participants also pointed out how in discovering more about themselves, their sense of selfesteem was increased, for example: "Prior to camp, I didn't really feel that good about myself. Once I started going to camp, I began to feel very good about myself" (Participant 3). Some participants went as far as to say that being at culture camp at times felt like their home, or rather being at home. Clearly, culture camp was for some participants a place of safety, a place of grounding, as it provided an increased sense of well-being. There were also references made to the new, cultural, and fun activities which served as adding meaning to participants' lives, giving them purpose and connectedness. While talking about becoming involved with the drumming group through culture camp, a youth said, "Friends are complimenting me on stuff [drumming] ... I'm hearing all these good comments and it's making me feel better about myself" (Participant 9). Participants referred to their growth and movement away from "childish" attitudes and reactions; for example a youth said that "after the camp I realized you have to give back for what you took and give thanks" (Participant 5).

\section{Attitudinal, behavioural, and developmental changes.}

This theme is concerned with how engaging and participating in culture camp had an effect on the youth's attitudes and behaviours regarding substance misuse and, more broadly, experiences of positive personal growth, development, and maturity. In regards to risk-taking behaviours, more than half of the youth indicated a reduced desire to drink alcohol and a reduced desire to take illegal drugs following camp. It should be acknowledged that the evidence pertaining to decreased substance use was not rich, as it was for our other themes; nevertheless, some participants made reference to how they learned new perspectives on drug and/or alcohol misuse or abuse as a direct result of listening to information provided during the camps. Participants made reference to how their views and behaviours were informed as a result of listening to the (often chilling) testimonies of recovering substance abusers. This real-world testimony appeared to be particularly compelling, given who was informing the participants (e.g., senior and influential figures in the cultural community); these individuals were described 
Nges Siy (I love you): A Community-Based Youth Suicide Intervention in Northern British Columbia • Henry G. Harder, Travis Holyk, Virginia L. Russell, Tammy Klassen-Ross

as highly respected or "looked up to" by the youth. Some participants reported feeling hopeful they could become an integral and senior member of the cultural community (similar to the leaders) despite having a background or history of substance misuse. Drinking - at times to excess-was not an uncommonly reported experience for some of the participants; in fact, substance use/misuse was seen as "ok," "acceptable," and even "cool" and a normal part of being a grown-up member in community. However, following culture camps, youth reported feeling challenged and impacted by the leaders (counsellors and elders) and their stories. Participant 2 described the experience of camps by saying, "... if I hadn't done any of the camps, I would probably have ended up going down the wrong path."

Participants made reference to activities and practices which were culturally specific and culturally significant and how they learned a great deal and grew as a result: not only learning about their culture and background, but also learning more about themselves. Personal growth, positive development, self-awareness, and identity were all commonly related to the acquirement of new skills (e.g., drumming; drying meat) and connections made (e.g., elders; cultural activities). Youth spoke about a number of unexpected developments including feeling more confident and less shy, being able to apply for paying jobs, changing their views and opinions about themselves, and inevitably moving from more negative and limiting views to more positive and encouraging views of self. A participant who attended five camps spoke about the positive impact and experiences directly related to the skills learned and relationships made, saying, "I would always be really sad to leave ... I thought it was better to do everything off the land and not have electronics ... just traditional music and that's it. I learned about my traditions ... fishing, medicines, music, language, canning, smoking ... you all have responsibilities that you have to get done by the end of the day ... and now I feel like, I don't know, I feel like I'm a role model to other kids now" (Participant 5).

\section{Challenges and Opportunities}

Chapter 9 of the Tri-Council Policy Statement on research ethics (TCPS2, 2014) is clear on the need to consult with Aboriginal communities prior to beginning any research study. Such consultation is meant to be meaningful and not cursory. Conducting such consultation with geographically widespread groups in northern British Columbia was a large challenge. People travelled great distances on bad roads in all kinds of weather to participate in the consultation, and their insights and wisdom were invaluable. The cost of such consultation was significant and involved a major part of our budget and thus would be difficult to replicate without a significant financial contribution.

Indigenous research methodologies require that benefits accrue to the Indigenous communities participating in the research. As a research team we were determined that this should happen. However, this concept is difficult for tri-council funding agencies, such as CIHR, to accept as they are vested in Western approaches to research. This tension was evident throughout the study. However, in the end we believe that both the communities and the academy at large benefited from these efforts. During the period of this study and directly associated with the methods employed, community support for the research and understanding of suicide prevention grew in each of the communities. Due to many competing factors such as meeting the needs of their home communities, it was a challenge to have Carrier First Nation members of the research team continue on to graduate school as proposed in the study design, but the project increased their knowledge of Western academic research theories and methods and several have now taken on substantial leadership roles in their communities. As part of the knowledge exchange, non-Carrier members of the research team grew in their knowledge and 
Nges Siy (I love you): A Community-Based Youth Suicide Intervention in Northern British Columbia • Henry G. Harder, Travis Holyk, Virginia L. Russell, Tammy Klassen-Ross

understanding of Carrier Sekani practice as well as Indigenous research methodologies. This coming together of local community members with the academic community was a strength of this study.

There is a tendency in Canada to lump all Indigenous people into one category and apply a one-size-fits-all solution to whatever problem is being addressed. This is evident when phrases like "an epidemic of Aboriginal teen suicide" are used to describe the issues or even using the term "culturally appropriate" within diverse communities. Some Indigenous communities have serious and tragic issues with suicide, while others have limited or no encounters with suicide. It seems grossly unfair to lump all into one category, especially when this results in one type of intervention that is employed to "solve" the problem. In the case of suicide prevention, Western approaches are "indigenized" and heralded as the solution to the problem. In fact, such approaches are worse than nothing. They foster colonization and the power of the dominant culture, in that they do not recognize the worldview of the particular Indigenous culture. Interventions, including suicide prevention for Indigenous Peoples, must be based on Indigenous epistemology and ontology if they are to be effective.

\section{Conclusions}

Culturally appropriate and culturally specific interventions can be created that have an impact on reducing adolescent Aboriginal suicide. By fostering good mental health and wellness, including pride in who one is and where one is from, leading indicators of suicide risk can be influenced in such a way that the person affected is less likely to make an attempt at suicide. Interventions must be designed uniquely for each community, and a pan-Indigenous approach must not be used. Such an approach takes time and commitment, but canned quick-fix interventions will not adequately address the root causes of suicidality that originate in historical trauma and the sequelae of colonization. Wellness of communities must take a holistic approach and absolutely must address all aspects of wellness, including health and wealth.

Chandler and Lalonde (1998) argued that cultural continuity and self-governance are a hedge, a preventative protectant, against suicide. We would add that it is hope for the future and how one fits into that future, while understanding and accepting one's own culture, that is a determinant of Indigenous community wellness and that this is the true mitigator of Aboriginal youth suicide.

\section{References}

Aboriginal Affairs and Northern Development Canada. (2012). Registered Indian population by sex and residence 2012. Retrieved from https://www.aadncaandc.gc.ca/eng/1373985023065/1373985196078

Adelson, N. (2005). The embodiment of inequalities: Health disparities in Aboriginal Canada. Canadian Journal of Public Health, 96, 45-61.

Aguiar, W., \& Halseth, R. (2015). Aboriginal Peoples and historic trauma: The processes of intergenerational transmission. Retrieved from National Collaborating Centre for Aboriginal Health website: http://www.nccahccnsa.ca/Publications/Lists/Publications/Attachments/142/2015_04_28_AguiarHalseth_R PT_IntergenTraumaHistory_EN_Web.pdf 
Nges Siy (I love you): A Community-Based Youth Suicide Intervention in Northern British Columbia • Henry G. Harder, Travis Holyk, Virginia L. Russell, Tammy Klassen-Ross

Battiste, M., Bell, L., \& Findlay, L. M. (2002). Decolonizing education in Canadian universities: An interdisciplinary, international, Indigenous research project. Canadian Journal of Native Education, 26(2), 82-95.

BC Statistics. (2015). Demography: Population Estimates. Retrieved October 27, 2015 from BC Stats: http://bcstats.gov.bc.ca/StatisticsBySubject/Demography/PopulationEstimates.aspx

Beck, A. T., \& Steer, R. A. (1988). Manual for the Beck Hopelessness Scale. San Antonio, TX: Psychological Corporation.

Beck, A. T., \& Steer, R. A. (1991). Manual for Beck Scale for Suicide Ideation. San Antonio, TX: Psychological Corporation.

Beck, A. T., Steer, R. A., \& Brown, G. K. (1996). Beck Depression Inventory manual (2nd ed.). San Antonio, TX: Psychological Corporation.

Blackstock, C. (2011). Why if Canada wins, Canadians lose: The Canadian Human Rights Tribunal on First Nations child welfare. Children and Youth Services Review, 33, 187194. doi:10.1016/j.childyouth.2010.09.002

Braun, V., \& Clarke, V. (2006). Using thematic analyses in psychology. Qualitative Research in Psychology, 3(2), 77-101. doi:10.1191/1478088706qp063oa

Brown, E. R. (1991). Community action for health promotion: A strategy to empower individuals and communities. International Journal of Health Services, 21(3), 441-456.

Chandler, M. J., \& Lalonde, C. (1998). Cultural continuity as a hedge against suicide in Canada's First Nations. Transcultural Psychiatry, 35(2), 191-219. doi:10.1177/136346159803500202

Chansonneuve, D. (2005). Reclaiming connections: Understanding residential school trauma among Aboriginal Peoples. Ottawa: ON: Aboriginal Healing Foundation.

Denzin, N., Lincoln, Y., \& Smith, L. T. (2008). Handbook of critical and Indigenous methodologies. Thousand Oaks, CA: Sage Publications. doi:10.4135/9781483385686

Hankivsky, O., \& Christoffersen, A. (2008). Intersectionality and the determinants of health: A Canadian perspective. Critical Public Health, 18(3), 271-283. doi:10.1080/09581590802294296

Health Canada. (2010). Acting on what we know: Preventing youth suicide in First Nations. Retrieved from dgspni/pdf/pubs/suicide/prev_youth-jeunes-eng.pdf 
Nges Siy (I love you): A Community-Based Youth Suicide Intervention in Northern British Columbia • Henry G. Harder, Travis Holyk, Virginia L. Russell, Tammy Klassen-Ross

Holyk, T., Shawana, P., \& Adam, W. (2005). Whu' Neeh Nee' (Guiders of Our People): Strengthening Lake Babine First Nation Law Through Research and Training. Invited Paper, presented at the World Indigenous Peoples Conference on Education. November 28 - December 1. Hamilton, New Zealand.

Israel, B. A., Schulz, A., Parker, E., \& Becker, A. (1998). Review of community-based research: Assessing partnership approaches to improve public health. Annual Review of Public Health, 29, 173-202. doi:10.1146/annurev.publhealth.19.1.173

Lopez, K. A., \& Willis, D. G. (2004). Descriptive versus interpretive phenomenology: Their contributions to nursing knowledge. Qualitative Health Research, 14, 726-735. doi:10.1177/1049732304263638

Loppie Reading, C., \& Wien, F. (2009). Health inequalities and social determinants of Aboriginal Peoples' health. Retrieved from National Collaborating Centre for Aboriginal Health website: http://www.nccah-ccnsa.ca/docs/social\%20determinates/NCCAH-loppieWien_report.pdf

Marmot, M., Friel, R., Bell, T., Howeling, T., \& Taylor, S. (2008). Closing the gap in a generation: Health equity through action on the social determinants of health. Lancet, 372, 1661-1669. doi:10.1016/s0140-6736(08)61690-6

Mental Health Commission of Canada. (2012). Changing directions, changing lives: The mental health strategy for Canada. Calgary, AB: Author.

Rosenberg, M. (1965). Society and the adolescent self-image. Princeton, NJ: Princeton University Press.

Royal Commission on Aboriginal Peoples. (1996). Report of the Royal Commission on Aboriginal Peoples (Vol. 3). Ottawa, ON: Indian and Northern Affairs.

Smith, L. T. (2012). Decolonizing methodologies. London, UK: Zed Books.

Statistics Canada. (2015). Aboriginal statistics at a glance (89-645-X): Population counts. Retrieved October 27, 2015 from Statistics Canada: http://statcan.gc.ca/pub/89-645x/2010001/count-pop-denombrement-eng.htm

TCPS2. (2014). Tri-council policy statement: Ethical conduct for research involving humans. Canadian Institutes of Health Research, Natural Sciences and Engineering Research Council of Canada, and Social Sciences and Humanities Research Council of Canada. Retrieved from Panel on Research Ethics website, Government of Canada: http://www.pre.ethics.gc.ca/pdf/eng/tcps2-2014/TCPS_2_FINAL_Web.pdf 